\title{
EDITORIALS
}

\section{Shared Decision Making, Contextualized}

\author{
Robert L. Ferrer, MD, MPH, Associate Editor ${ }^{1}$ \\ James M. Gill, MD, MPH, Associate Editor ${ }^{2-4}$ \\ Ann Fam Med 2013;303-305. doi:10.1370/afm.1551.
}

We are what we repeatedly do. Excellence, then, is not an act, but a babit.

Will Durant, paraphrasing Aristotle

$\mathrm{P}$ atient-centeredness is a core aspiration of health care. ${ }^{2}$ Rooted in the ethical proposition of autonomy, patient-centeredness enables patients to align the care they get with the care they want. It is an approach to practice built on whole-person knowledge, respect for patients' preferences, and fostering a productive clinician-patient relationship. ${ }^{3}$

One sign of patient-centered care is that important choices are made through shared decision making. Shared decision making helps patients and their loved ones to make informed decisions by bringing together patients' preferences, scientific evidence on outcomes, and clinicians' expertise in integrating clinical circumstances, values, and evidence. Professional organizations and patient advocacy groups ${ }^{4}$ alike recommend shared decision making, particularly where the answer depends on personal values, where the evidence is not definitive, or where the balance of risks and benefits varies widely in different medical, social, and health care situations.

This issue contains 3 articles that address shared decision making in prostate cancer screening. Although these studies were overtaken by events in 2012 as the US Preventive Services Task Force downgraded its prostate-specific antigen (PSA) screening recommendation from insufficient evidence ${ }^{5}$ to recommends against, ${ }^{6}$ they provide a valuable snapshot of performance for a difficult decision commonly encountered during a period when shared decision making was strongly recommended for PSA screening. The implications for the future development of shared decision making in primary care are explored below.

Han and colleagues examined data from a representative sample of US men aged 50 to 74 years on whether their physicians had discussed the advantages, disadvantages, or uncertainties of PSA screening. ${ }^{7}$

They discovered that $88 \%$ of unscreened men and $39 \%$ of men undergoing annual or near-annual screening received no elements of shared decision making.

Wilkes and colleagues organized a randomized trial of strategies to enhance shared decision making. ${ }^{8}$ They compared usual care with Web-based physician education alone or combined with patient activation. Patients reported modest degrees of shared decision making, with no differences in ratings from actual or standardized patients (actors trained to play clinical scenarios) across the 3 study arms. Intervention group physicians were, however, less likely to make recommendations for or against PSA testing.

Additional analysis of those standardized patients' audio-recorded visits is reported by Feng et al. ${ }^{9}$ Scores for the most patient-centered elements of shared decision making - in which physicians try to understand patients' preexisting knowledge, concerns, and preferences-were especially low, echoing another recent study with direct observations. ${ }^{10}$ The excerpted quotes also show how seldom physicians quantify risk. At times they merely acknowledge that there are choices and trade-offs. When they do quantify probabilities, they rely on such descriptors as most, a lot, some, and many. These vague quantifiers undermine shared decision making, because patients vastly overestimate benefits from PSA and other screening tests. ${ }^{11}$ Instead, informed decisions require marginal probabilities of risk and benefit, presented in a format the patient can understand. ${ }^{12}$

Consistent with the literature on shared decision making for prostate screening ${ }^{13}$ and other conditions, ${ }_{1}^{14}$ these 3 articles convey the message that shared decision making remains poorly integrated into primary care practice. When asked, clinicians acknowledge their performance falls short of ideals and identify needs for more helpful materials, training, information systems to support shared decision making, and time..$^{15}$

What is the way forward?

A common trap in primary care is to consider problems in isolation, failing to respect its multidimensional and longitudinal nature. ${ }^{16}$ Potential solutions must be in harmony with larger patterns of patients' lives and 
clinical practice. Three of those patterns relevant to shared decision making include patients' need to confront multiple decisions over time; decision making in the context of trusted relationships; and the place of shared decision making in primary care systems called upon to fulfill many essential functions.

A recent national survey ${ }^{17}$ estimated that in a 2-year span $82 \%$ of people older than 40 years will face at least 1 of the 9 health care decisions examined (cancer screenings, long-term medications, surgeries), and 56\% will face more than 1 . So rather than implementing a series of disease-specific shared decision-making interventions, it would make sense to approach shared decision making developmentally, as a learned skill. Each decision presents an opportunity to deepen patients' experience and understanding of shared decision making. This longitudinal approach is consistent with promoting patients' higher level goals: not what happens to a specific body part, but achieving a desired level of autonomy, empowerment, and functioning. ${ }^{18,19}$ To advance individuals' progress in shared decision making, practices should develop a general strategy that is adaptable to specific issues. For example, patients could be prepared to expect previsit educational materials before key decisions or decision aids for different interventions could be structured in parallel formats. Because small practices are unlikely to create these materials on their own, coordination among the many organizations developing decision aids would be needed to achieve consistency.

A developmental perspective on shared decision making extends to the trusting relationships on which it depends. Recurring dialogue allows clinicians and patients to learn the other's perspective and communication style. Patients view the clinician's opinion as valuable in itself, something that helps them distill complex information received through other channels. ${ }^{20}$ This principle is eloquently developed in Epstein and colleagues' recent work describing "shared mind," the notion that difficult decisions are often best reached through dialogue, iteratively, coping with insufficient information, shifting and conditional preferences, and the perspectives of different people important to the patient. ${ }^{21}$ Carefully exploring these issues can help overcome known decision-making biase $^{22}$ and produce more stable decisions.

Many clinicians view such integrative care as a core responsibility. Yet shared decision making is just one of many functions primary care clinicians must balance with other competing demands. Herein lies a problem that the literature thus far sidesteps: Is shared decision making a distinct subroutine invoked for a limited number of critical decisions? Or is it a daily practice, as is history taking, that clinicians regularly enter and exit? Although clinicians may not be engaging in fullon shared decision making with decision aids, they frequently enter into less-intensive dialogue around patients' wishes:

Patient: I'm on so many pills after my heart attack, I don't want to add another one. Let me try diet a bit longer.

Doctor: Yes, we can help you understand how to make more extensive changes in your diet. But most patients find it difficult to lower their LDL by 80 points without radical changes. What would you like to do?

This probably explains why nearly all physicians report they engage in shared decision making ${ }^{23}$ even when observations show that few deliver the idealized version. Acknowledging a spectrum of shared decision making better reflects clinical reality, though it does not obviate the need to improve performance.

If we accept the premise that shared decision making is less a discrete act than a skill to be cultivated through repeated application within meaningful relationships, we can reframe our approach in a broader context, giving attention to unanswered questions, conflicting demands, and systems implications:

- How should we balance the personalized health care and population/public health roles in shared decision making? Widespread misperceptions about interventions' efficacy ${ }^{10}$ suggest that population-based education could put subsequent clinical discussions on a firmer foundation. In fact, programs to educate patients outside the clinical setting are already being tested. For example, health plans have contracted with population-management firms to distribute education materials and make health coaches available to discuss options by telephone with members likely to face decisions for preference-sensitive conditions. ${ }^{24}$ Beyond payer-based programs, the continuing growth of online social networking will help patients participate more actively in decisons. ${ }^{25}$

- When more intensive shared decision making is needed, how can we make it practical in an already crowded primary care workday?:26,27 Many are recommending a team approach, ${ }^{28}$ although careful thought must be given to which staff in evolving primary care models have sufficient knowledge, relationship, and continuity to integrate the biotechnical and the biographical. And if we expect clinicians to engage patients in shared decision making, their time needs to be reimbursed. One model for this is CPT coding for tobacco or weight management counseling.

- How do we best train clinicial teams and support their development in shared decision making?

- What boundaries should be placed on shared decision making? What are the opportunity costs when 
the scarcest resources in health care-time and attention-are potentially devoted to discussing topics of marginal benefit (like PSA screening after the new USPSTF recommendation), potentially diverting attention from topics of greater importance?

- What is the spectrum of need in diverse populations? For whom is the standard shared decision-making solution likely to fail and how do we adapt?

Shared decision making is such a good idea that we seldom step back to look at the larger picture. Raising our performance means doing exactly that, treating shared decision making, not as an episodic event, but as an ongoing process within patients' lives and the practices of those who care for them.

To read or post commentaries in response to this article, see it online at http://www.annfammed.org/content/11/4/303.

Key words: patient-centered care; decision making, shared

Submitted May 17, 2013; submitted, revised, May 17, 2013, accepted May 23, 2013

\section{References}

1. Durant W. The Story of Philosophy. New York, NY: Simon \& Schuster, Inc; 1991.

2. Institute of Medicine. Crossing the Quality Chasm: A New Health System for the 21st Century. Washington, DC: National Academy Press; 2001

3. Stewart M, Brown JB, Eston WW, McWhinney IR, McWilliam CL, Freeman TR. Patient-centered Medicine: Transforming the Clinical Method. 2nd ed. Abingdon, UK: Radcliffe Medical Press; 2003.

4. Salzburg Global Seminar. Salzburg statement on shared decision making. BMJ. 2011;342:d1745.

5. U.S. Preventive Services Task Force. Screening for prostate cancer: U.S. Preventive Services Task Force recommendation statement. Ann Intern Med. 2008;149(3):185-191.

6. Moyer VA; U.S. Preventive Services Task Force. Screening for prostate cancer: U.S. Preventive Services Task Force recommendation statement. Ann Intern Med. 2012;157(2):120-134.

7. Han PKJ, Kobrin S, Breen N, et al. National evidence on the use of shared decision making in prostate-specific antigen screening. Ann Fam Med. 2013;11(4):306-314.

8. Wilkes MS, Day FC, Srinivasan M, et al. Pairing physician education with patient activation to improve shared decisions in prostate cancer screening: a cluster randomized controlled trial. Ann Fam Med. 2013;11(4):324-334.

9. Feng B, Srinivasan M, Hoffman JR, et al. Physician communication regarding prostate cancer screening: analysis of unannounced standardized patient visits. Ann Fam Med. 2013;11(4):315-323.
10. Leader A, Daskalakis C, Braddock CH III, et al. Measuring informed decision making about prostate cancer screening in primary care. Med Decis Making. 2012;32(2):327-336.

11. Gigerenzer G, Mata J, Frank R. Public knowledge of benefits of breast and prostate cancer screening in Europe. J Natl Cancer Inst. 2009;101(17):1216-1220.

12. McNutt RA. Shared medical decision making: problems, process, progress. JAMA. 2004;292(20):2516-2518.

13. Hoffman RM, Couper MP, Zikmund-Fisher BJ, et al. Prostate cancer screening decisions: results from the National Survey of Medical Decisions (DECISIONS study). Arch Intern Med. 2009;169(17):1611-1618.

14. Flocke SA, Stange KC, Cooper GS, et al. Patient-rated importance and receipt of information for colorectal cancer screening. Cancer Epidemiol Biomarkers Prev. 2011;20(10):2168-2173.

15. Friedberg MW, Van Busum K, Wexler R, Bowen M, Schneider EC. A demonstration of shared decision making in primary care highlights barriers to adoption and potential remedies. Health Aff (Millwood). 2013;32(2):268-275.

16. Ferrer RL, Hambidge SJ, Maly RC. The essential role of generalists in health care systems. Ann Intern Med. 2005;142(8):691-699.

17. Zikmund-Fisher BJ, Couper MP, Singer E, et al. The DECISIONS study: a nationwide survey of United States adults regarding 9 common medical decisions. Med Decis Making. 2010;30(5)(Suppl):20S-34S.

18. MCVea KL, Minier WC, Johnson Palensky JE. Low-income women with early-stage breast cancer: physician and patient decisionmaking styles. Psychooncology. 2001;10(2):137-146.

19. Mandelblatt JS, Edge SB, Meropol NJ, et al. Predictors of long-term outcomes in older breast cancer survivors: perceptions versus patterns of care. J Clin Oncol. 2003;21(5):855-863.

20. Alston C, Paget L, Halvorson G, et al. Communicating with Patients on Health Care Evidence. Washington, DC: Institute of Medicine; 2012. http://www.iom.edu/evidence.

21. Epstein RM, Gramling RE. What is shared in shared decision making? Complex decisions when the evidence is unclear. Med Care Res Rev. 2013;70(1)(Suppl):94S-112S.

22. Tversky A, Kahneman D. Judgement under uncertainty: heuristics and biases. Science. 1974;185(4157):1124-1131.

23. King VJ, Davis MM, Gorman PN, Rugge JB, Fagnan LJ. Perceptions of shared decision making and decision aids among rural primary care clinicians. Med Decis Making. 2012;32(4):636-644.

24. Veroff D, Marr A, Wennberg DE. Enhanced support for shared decision making reduced costs of care for patients with preferencesensitive conditions. Health Aff (Millwood). 2013;32(2):285-293.

25. Griffiths F, Cave J, Boardman F, et al. Social networks-the future for health care delivery. Soc Sci Med. 2012;75(12):2233-2241.

26. Yarnall KSH, Pollak KI, Østbye T, Krause KM, Michener JL. Primary care: is there enough time for prevention? Am J Public Health. 2003;93(4):635-641.

27. Østbye T, Yarnall KSH, Krause KM, Pollak KI, Gradison M, Michener $\mathrm{JL}$. Is there time for management of patients with chronic diseases in primary care? Ann Fam Med. 2005;3(3):209-214.

28. Légaré F, Witteman HO. Shared decision making: examining key elements and barriers to adoption into routine clinical practice. Health Aff (Millwood). 2013;32(2):276-284. 